Article

\title{
Apple Pomace Extract as a Sustainable Food Ingredient
}

\author{
Pedro A. R. Fernandes ${ }^{1}$, , Sónia S. Ferreira ${ }^{1}$, Rita Bastos ${ }^{1}$, Isabel Ferreira ${ }^{2}$, Maria T. Cruz ${ }^{2}$, \\ António Pinto ${ }^{3,4,5}$, Elisabete Coelho ${ }^{1}$, Cláudia P. Passos ${ }^{1}$, Manuel A. Coimbra ${ }^{1}$ (D, \\ Susana M. Cardoso $1, *(\mathbb{D})$ and Dulcineia F. Wessel $1,3,4, * \mathbb{D}$ \\ 1 QOPNA \& LAQV-REQUIMTE, Department of Chemistry, University of Aveiro, 3810-193 Aveiro, Portugal; \\ pedroantonio@ua.pt (P.A.R.F.); soniasferreira@ua.pt (S.S.F.); ritabastos@ua.pt (R.B.); ecoelho@ua.pt (E.C.); \\ cpassos@ua.pt (C.P.P.); mac@ua.pt (M.A.C.) \\ 2 Faculty of Pharmacy and Center of Pharmaceutical Studies, University of Coimbra, Azinhaga de Santa \\ Comba, 3000-548 Coimbra, Portugal; isabelcvf@gmail.com (I.F.); trosete@ff.uc.pt (M.T.C.) \\ 3 School of Agriculture and CI\&DETS, Polytechnic Institute of Viseu, 3500-606 Viseu, Portugal; \\ apinto@esav.ipv.pt \\ 4 CITAB, University of Trás-os-Montes e Alto Douro, 5001-801 Vila Real, Portugal \\ 5 CERNAS, Agrarian Higher School, 3045-601 Coimbra, Portugal \\ * Correspondence: susanacardoso@ua.pt (S.M.C.); ferdulcineia@esav.ipv.pt (D.F.W.); \\ Tel.: +351-234-370-360 (S.M.C.); +351-232-480-703 (D.F.W.)
}

Received: 9 April 2019; Accepted: 16 June 2019; Published: 21 June 2019

check for updates

\begin{abstract}
Apple pomace is a by-product of apple processing industries with low value and thus frequent disposal, although with valuable compounds. Acidified hot water extraction has been suggested as a clean, feasible, and easy approach for the recovery of polyphenols. This type of extraction allowed us to obtain $296 \mathrm{~g}$ of extract per $\mathrm{kg}$ of dry apple pomace, including $3.3 \mathrm{~g}$ of polyphenols and $281 \mathrm{~g}$ of carbohydrates. Ultrafiltration and solid-phase extraction using C18 cartridges of the hot water extract suggested that, in addition to the apple native polyphenols detected by ultra-high-pressure liquid chromatography coupled to a diode-array detector and mass spectrometry UHPLC-DAD-ESI-MS ${ }^{n}$, polyphenols could also be present as complexes with carbohydrates. For the water-soluble polyphenols, antioxidant and anti-inflammatory effects were observed by inhibiting chemically generated hydroxyl radicals $(\mathrm{OH} \bullet)$ and nitrogen monoxide radicals $(\mathrm{NO} \bullet)$ produced in lipopolysaccharide-stimulated macrophages. The water-soluble polyphenols, when incorporated into yogurt formulations, were not affected by fermentation and improved the antioxidant properties of the final product. This in vitro research paves the way for agro-food industries to achieve more diversified and sustainable solutions towards their main by-products.
\end{abstract}

Keywords: polyphenols; antioxidant; anti-inflammatory; extraction; functional food

\section{Introduction}

The fact that agro-food industrial by-products are generally disposed, often with great expenses and environmental implications, has raised the need for their valuation [1]. Their perishable nature, due to the high-water content and huge amounts of organic load, as well as their chemical composition, particularly in dietary fiber and phytochemicals, provides a costless source of bioactive compounds that may favor an efficient and sustainable industrial development [1,2]. As a matter of fact, a circular economy model can be implemented in the agro-food sector by recycling its by-products, thereby creating added value with fewer resources.

Among the wide variety of agro-food industrial by-products available worldwide, apple pomace, resultant from apple (Malus spp., Rosaceae) processing, can be highlighted given the ubiquitous 
presence of the fruit in the diet of all cultures [3]. Actually, every year millions of tons of apples are processed to produce apple cider, juices, or concentrates, which yield huge amounts of residues, comprising the pulp, skin, seeds, and stalks from the fruit [2]. Several strategies for the valuation of apple pomace have been proposed, including its direct use for animal feed, organic acids, enzymes, bioethanol and biogas production by microbial fermentation, or the development of new materials as part of biocomposites [4]. Nevertheless, this by-product still presents a significant edible fraction which can be used as a source of valuable components. These may include hydroxycinnamic acids (chlorogenic acid and $p$-coumaroylquinic acid), flavan-3-ols (monomers such as epicatechin to large polymers known as procyanidins), flavonols (quercetin rutinoside, galactoside, glucoside, xyloside, arabinoside, and rhamnoside derivatives), dihydrochalcones (phloretin 2-O-glucoside and phloretin 2-O-xyloglucoside), and anthocyanins (cyanidin 3-O-galactoside) [2,5,6]. Furthermore, given the occurrence of polyphenol oxidation reactions, polyphenols might also be found as components attached to cell wall polysaccharides $[7,8]$, which may have an impact on the antioxidant and antiviral properties attributed to apple pomace extracts [9]. Most studies aiming to evaluate the potential applications of apple pomace valuable components have been performed with the use of organic solvents, which may be appropriate for pharmaceutical or cosmetic purposes but not for food applications.

Therefore, this work aims to give new insights into the nature of the apple pomace water-soluble polyphenols and their bioactivity, as well as to evaluate the potential of its water extract to be used for the supplementation or development of fortified products. To this end, in addition to apple native polyphenols, the occurrence of polyphenol/carbohydrate complexes was inferred employing ultrafiltration and solid-phase extraction of the hot water extract. Furthermore, the polyphenols isolated by solid-phase extraction were also used to provide evidence of their antioxidant and anti-inflammatory properties using both chemical and cellular inflammatory models. The feasibility of incorporating the aqueous extract of apple pomace into foods was tested by its addition to yogurt formulations and its potential impact on the fermentation process $(\mathrm{pH}$, titratable acidity, and lactic acid counting), and antioxidant and nutritional properties of the final product.

\section{Materials and Methods}

\subsection{Chemicals}

All reagents were of analytical grade. All standard compounds used for polyphenol quantification by UHPLC-DAD-ESI-MS ${ }^{n}$ or antioxidant assays had a purity level of at least $95 \%$.

\subsection{Preparation of Extracts}

Agro-industrial apple pomace was obtained following the general procedure described by Kennedy et al. [10]. This process consisted of the processing of a mixture of apples, mainly composed of the Royal Gala variety, employing milling, enzymatic digestion (amylase, pectin lyase, and polygalacturonase), and pressing processes for a period of at least 3 hours. After processing, the apple pomace was frozen at $-20^{\circ} \mathrm{C}$, freeze-dried, sealed in bags, and stored in a dark at room temperature in a desiccator until further analysis. Extracts were prepared from apple pomace, using boiling water with $1 \%$ acetic acid, $\mathrm{pH} 2.5$, at a solid (dry weight) to a solvent ratio of 1:60 (g/mL), the optimal conditions for polyphenol extraction as determined by Çam and Aaby [5]. The procedure was limited to a period of $10 \mathrm{~min}$ as the extraction yields (in mass) hardly improved for more than $10 \%$ using longer periods, e.g., 1 or $2 \mathrm{~h}$, and allowed us to avoid the polyphenols thermal degradation [11,12]. Afterwards, the extracts were filtered (Whatman filter paper $\mathrm{n}^{\circ} 4$ and G3 sintered funnel), and the residue was re-extracted two more times following the same procedure to recover any remnant material. The crude extracts were combined, concentrated under reduced pressure, and freeze-dried, yielding a hot water extract (HWE). For characterization of the high and low molecular weight material (Figure 1), the HWE was fractionated at room temperature on an ultrafiltration module - Labscale TFF System (Merck KGaA, 
Darmstadt, Germany), using a pellicon XL ultrafiltration ultracel membrane with cut-off $10 \mathrm{kDa}$, as previously described by Passos et al. [13].

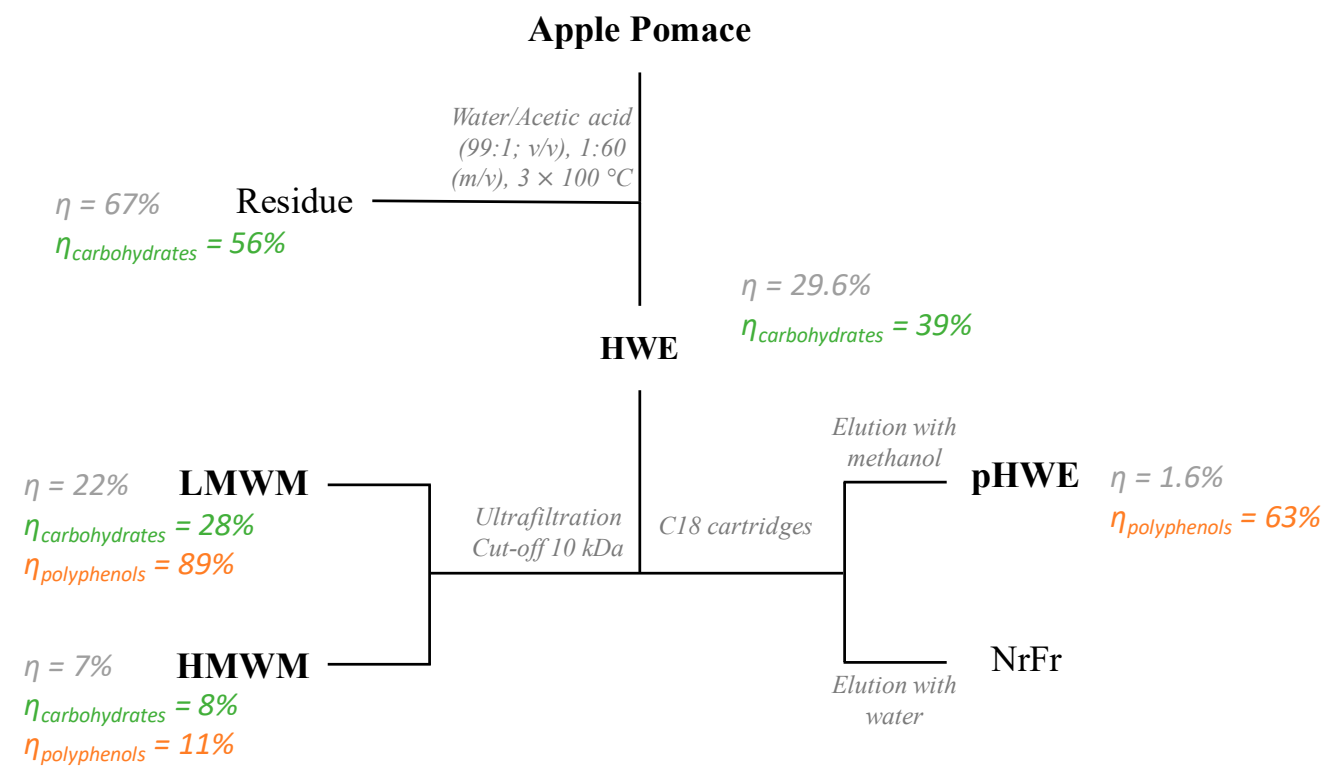

Figure 1. Schematic representation of the fractionation processes adopted in this work and yields of the extracts and polysaccharides in relation to apple pomace and polyphenols present in the hot water extract (dry basis). In bold are highlighted the fractions that were further studied. HWE-hot water extract; LMWM-low molecular weight material; HMWM-high molecular weight material; pHWE-purified hot water extract; $\mathrm{NrFr}$-non-retained fraction.

To further characterize the polyphenolic composition and potential bioactive effects, the HWE was submitted to solid-phase extraction (Figure 1) in Sep-Pak C18 cartridges (SPE-C18, Supelco-Discovery (St. Louis, MO, USA, $20 \mathrm{~g}$ ). The column was preconditioned with $20 \mathrm{~mL}$ of methanol followed by $20 \mathrm{~mL}$ of water. Afterwards, the sample was loaded onto the column, and the non-retained material ( $\mathrm{NrFr})$ was eluted with water, three times the volume of the cartridge. The material retained was eluted using methanol following the same procedure. The resultant polyphenol-isolated HWE fraction (pHWE) was concentrated under reduced pressure to remove the methanol and then frozen and freeze-dried.

For the fractionation processes by ultrafiltration or solid-phase extraction using C18 cartridges, polyphenols yields were estimated by mass balance between those initially found in the hot water extract and those obtained in the further sub-fractions. For ultrafiltration it was estimated as described in Equation (1):

$$
\text { PCHWE }=\text { PCHMWM }+ \text { PCLMWM }
$$

where, PCHWE, PCHMWM, and PCLMWM corresponds to the mass of polyphenols present in the HWE, high molecular weight material fraction, and low molecular weight material fractions, respectively.

For solid phase extraction the yields were estimated considering Equation (2):

$$
\mathrm{PCHWE}=\mathrm{PC} \text { PHWE }+\mathrm{PCNrFr}
$$

where PCHWE, PCpHWE, and PCNrFr corresponds to the mass of polyphenols present in the HWE, in the fraction retained in the C18 cartridges (pHWE), and in the non-retained fraction in the C18 cartridge $(\mathrm{NrFr})$, respectively. For polysaccharides, a similar rationale was applied taking as a reference the number of polysaccharides initially present in the apple pomace. 


\subsection{General Chemical Characterization}

The moisture content of apple pomace was determined by the weight difference before and after drying for $12 \mathrm{~h}$ at $105^{\circ} \mathrm{C}$, up to constant weight. For apple pomace and derived extracts, protein was estimated by determining total nitrogen using a Truspec 630-200-200 elemental analyzer (St. Joseph, MI, USA) with a thermal conductivity detector (TDC) and employing a conversion factor of 5.72, as estimated for apples [14]. To obtain quantitative and qualitative information, the carbohydrate composition of the samples was determined by adopting the general procedure of Fernandes et al. [8]. Briefly, neutral sugars were determined using gas chromatography (GC) analysis after acid hydrolysis $\left(12 \mathrm{M} \mathrm{H}_{2} \mathrm{SO}_{4}\right.$ for $3 \mathrm{~h}$ at room temperature, followed by $2.5 \mathrm{~h}$ hydrolysis in $1 \mathrm{M} \mathrm{H}_{2} \mathrm{SO}_{4}$ at $100{ }^{\circ} \mathrm{C}$ ), reduction with $\mathrm{NaBH}_{4}\left(15 \% \mathrm{w} / \mathrm{v}\right.$ in $3 \mathrm{M} \mathrm{NH}_{3}$ during $1 \mathrm{~h}$ at $\left.30{ }^{\circ} \mathrm{C}\right)$, and acetylation (with acetic anhydride in the presence of 1 -methylimidazole during $30 \mathrm{~min}$ at $30^{\circ} \mathrm{C}$ ). Uronic acids were quantified by the 3-phenylphenol colorimetric method after acid hydrolysis ( $1 \mathrm{~h}$ in $1 \mathrm{M} \mathrm{H}_{2} \mathrm{SO}_{4}$ at $\left.100{ }^{\circ} \mathrm{C}\right)$ of the sample [15]. Galacturonic acid (GalA) was used as standard. Free sugars were determined following the same procedure without the hydrolysis step. Fructose was quantified as the sum of mannitol and sorbitol due to the epimerization of fructose during the reduction step, using the ratio of the epimerization reaction [16]. The amount of total polyphenolic compounds was quantified using the Folin-Ciocalteu method [17] using concentrations from 1 to $10 \mathrm{mg}$ of extract/mL water. The results were expressed as g gallic acid equivalent (GAE)/kg of extract.

Individual polyphenols were determined by UHPLC-DAD-ESI-MS ${ }^{\mathrm{n}}$ on an Ultimate 3000 (Dionex Co., San Jose, CA, USA) apparatus equipped with a Diode Array Detector (Dionex Co., USA) and coupled to a mass spectrometer. The chromatographic system consisted of a quaternary pump, an autosampler, a degasser, a photodiode-array detector, and an automatic thermostatic column compartment. Hypersil Gold (Thermo Scientific, San Jose, CA, USA) C18 column (100 mm length; $2.1 \mathrm{~mm}$ i.d.; $1.9 \mu \mathrm{m}$ particle diameter, end-capped) at $30{ }^{\circ} \mathrm{C}$ was used. The mobile phase was composed of (A) $0.1 \%(\mathrm{v} / \mathrm{v})$ formic acid and (B) acetonitrile. The solvent gradient started with $5 \%$ of solvent (B), reaching $40 \%$ at $14 \mathrm{~min}$ and $100 \%$ at $16 \mathrm{~min}$, followed by the return to the initial conditions. The flow rate was $0.1 \mathrm{~mL} \mathrm{~min}^{-1}$ and UV-Vis spectral data for all peaks were accumulated in the range 200-500 nm, while the chromatographic profiles were recorded at 280, 320, and $340 \mathrm{~nm}$ for polyphenol analysis. The mass spectrometer used was a Thermo LTQ XL (Thermo Scientific, USA) ion trap MS, equipped with an electrospray ionization (ESI) source. Control and data acquisition were carried out with the Thermo Xcalibur Qual Browser data system (Thermo Scientific, USA). Nitrogen above $99 \%$ purity was used, and the gas pressure was $520 \mathrm{kPa}(75 \mathrm{psi})$. The instrument was operated in negative-ion mode with ESI needle voltage set at $5.00 \mathrm{kV}$ and an ESI capillary temperature of $275^{\circ} \mathrm{C}$. The full scan covered the mass range from $\mathrm{m} / \mathrm{z} 100$ to 2000. CID-MS/MS and MS ${ }^{\mathrm{n}}$ experiments were acquired for precursor ions using helium as the collision gas with an energy of 25-35 arbitrary units.

For quantitative analysis, calibration curves were performed by injection of 5 known concentrations of standard compounds. Detection (LOD) and quantification (LOQ) limits were calculated using the parameters of the calibration curves, defined as 3.3 and 10 times the value of the regression error divided by the slope, respectively.

For rutin (ACROS), the tested range was 1.0-10.0 $\mu \mathrm{g} / \mathrm{mL}$, and the equation was $\mathrm{y}=12,624 \mathrm{x}-953$, with an $R^{2}$ value of 0.999 . The quantification limit (LQ) and detection limit (LD) for this compound were 1.29 and $0.43 \mu \mathrm{g} / \mathrm{mL}$, respectively. For quercetin-3-O-glucoside (Sigma-Aldrich), the tested range was $2.4-12.2 \mu \mathrm{g} / \mathrm{mL}$, the equation was $\mathrm{y}=16,421 \mathrm{x}-879$ with an $R^{2}$ value of 0.999 . The LQ and LD were 1.07 and $0.35 \mu \mathrm{g} / \mathrm{mL}$, respectively. The calibration curve of phloridzin (Sigma-Aldrich), $y=20,429 x-456$, were performed for ranges of $2.3-11.7 \mu \mathrm{g} / \mathrm{mL}$, presenting an $R^{2}$ of 0.999 . The determined LQ and LD were 1.35 and $0.45 \mu \mathrm{g} / \mathrm{mL}$, respectively. The remaining quercetin derivatives were quantified as quercetin-3-O-glucoside equivalents. 


\subsection{Formulation of a Hot Water Extract (HWE)-Fortified Yogurt}

The apple pomace HWE was used as an ingredient for yogurt formulations. Yogurts were prepared from ultra-high temperature pasteurized milk (composed of $5.1 \%$ of carbohydrates, $3.4 \%$ of protein, and $1.6 \%$ of fat) and milk powder at $1 \% \mathrm{w} / \mathrm{w}$ of milk (composed of $54 \%$ of carbohydrates, $34.5 \%$ of protein, and $1 \%$ of fat) in the absence of, or alternatively with the addition of, extract, to yield a control yogurt and a supplemented yogurt, respectively. A ratio of $3.3 \%$ ( $\mathrm{w}$ of extract $/ \mathrm{w}$ of milk) was used based on the maximum amount of extract soluble in milk after heating to $90^{\circ} \mathrm{C}$ for $2 \mathrm{~min}$ and leaving to cool to $40{ }^{\circ} \mathrm{C}$. Plain yogurt (composed of $4.0 \%$ of carbohydrates, $3.2 \%$ of protein, and $2.9 \%$ of fat), purchased at the local market, was added ( $1 \% \mathrm{w} / \mathrm{w}$ of milk) as inoculum to achieve a final Lactic Acid Bacteria count of 6 Log colony forming units (CFU)/g of mixture. This amount was determined based on the Streptococcus thermophilus counts present in the commercial yogurt and detected in M17 (Liofilchem, Rosetodegli Abruzzi, Italy), a medium specific for the growth of this bacterium. An incubation period of $72 \mathrm{~h}$ at $37^{\circ} \mathrm{C}$ was used for Streptococcus thermophilus counting. For yogurt production, the mixture was incubated at $42{ }^{\circ} \mathrm{C}$ until reaching a $\mathrm{pH}$ below 4.5. The fermentation process was controlled by measuring the $\mathrm{pH}$, titratable acidity (g of lactic acid/100 g), and Streptococcus thermophilus counts every 2 hours. For titratable acidity, samples were homogenized in water at a proportion of 1:9 (w/v). Afterwards, the $\mathrm{pH}$ value of the samples was measured, and titrated with $0.1 \mathrm{M} \mathrm{NaOH}$ in the presence of a few drops of phenolphthalein (1\%) as an indicator. The titratable acidity was expressed in $\mathrm{g}$ of lactic equivalents/100 $\mathrm{g}$ of yogurt.

\subsection{Antioxidant Activity}

HWE and pHWE antioxidant activity was screened by the 2,2-diphenyl-1-picrylhydrazyl $(\mathrm{DPPH} \bullet)$ [18] and 2,2' -azinobis-(3-ethylbenzothiazoline-6-sulfonic acid) (ABTS $\bullet^{+}$) methods [19], using water as a solvent. The results were expressed as half maximum effective concentration $\left(\mathrm{EC}_{50}\right)(\mu \mathrm{g} / \mathrm{mL})$, which represents the amount of extract required to reduce the radical concentration to half of its initial concentration. In addition, pHWE was evaluated for its capability to inhibit $\mathrm{OH} \bullet$ radicals generated by the ferric-ascorbate-EDTA- $\mathrm{H}_{2} \mathrm{O}_{2}$ Fenton system, following the general procedure of Kunchandy and Rao [20]. The scavenging of $\mathrm{OH} \bullet$ was measured by determining the relative amount of oxidized deoxyribose formed in the presence and absence of the extract. The results were expressed as mannitol equivalents ( $\mathrm{mmol} / \mathrm{g}$ of extract). As the $\mathrm{OH} \bullet$ scavenging is based on the inhibition of deoxyribose oxidation by antioxidants, other sugars present, such as those found in the HWE, could interfere. For this reason, the antioxidant activity was measured on pHWE, obtained by purification of the HWE by solid-phase extraction.

To evaluate the effect of HWE addition to yogurts, total polyphenolic content and antioxidant activity, as well as their stability along the fermentation process, the control and supplemented yogurt with the HWE were individually extracted twice with methanol/water/acetic acid solutions (80:19:1; $\mathrm{v} / \mathrm{v} / \mathrm{v}$ ) along different fermentation times. The resulting extracts were concentrated, freeze-dried, and analyzed by the Folin-Ciocalteu protocol ( $\mu \mathrm{g}$ GAE/100 g of yogurt fresh weight). For the antioxidant activity, the ABTS $\bullet^{+}$method ( $\mu \mathrm{g}$ Trolox equivalents/100 $\mathrm{g}$ of yogurt fresh weight) was selected given its simplicity. The same concentrations and solvents as those described for the HWE and pHWE extracts were used.

\subsection{Anti-Inflammatory Potential}

\subsubsection{Inhibition of Chemically-Induced NO• Production}

The NO• scavenging method was adapted from Catarino et al. [21]. Briefly, $100 \mu \mathrm{L}$ of the pHWE, solubilized in phosphate buffer at pH 7.4 at $(260 \mu \mathrm{g} / \mathrm{mL})$, was mixed with $100 \mu \mathrm{L}$ of sodium nitroprusside $3.33 \mathrm{mM}$ (also in buffer) and incubated under a fluorescent lamp (Tryun $26 \mathrm{~W}$ ) for $15 \mathrm{~min}$. Afterwards, $100 \mu \mathrm{L}$ of Griess reagent $(0.5 \%$ sulphanilamide and $0.05 \%$ naphthyletylenediamine 
dihydrochloride in $2.5 \% \mathrm{H}_{3} \mathrm{PO}_{4}$ ) was added, and the mixture was incubated in the dark for $10 \mathrm{~min}$. The absorbance was measured at $562 \mathrm{~nm}$. NO• scavenging was expressed as \% of inhibition.

\subsubsection{Inhibition of NO• Production in LPS-Stimulated Macrophages Cell Line Raw 264.7}

The extracts were solubilized in sterile phosphate-buffered saline (PBS) with $2 \%(\mathrm{v} / \mathrm{v})$ dimethyl sulfoxide (DMSO) and filtered through a cellulose acetate $0.22 \mu \mathrm{m}$ sterile syringe filter (Frilabo, Maia, Portugal) under sterile conditions. The solutions were then diluted to achieve 281-1490 $\mu \mathrm{g} / \mathrm{mL}$ of $\mathrm{pHWE}$ in the culture medium, with a final concentration of dimethyl sulfoxide (DMSO) lower than $0.1 \%(\mathrm{v} / \mathrm{v})$. The medium was composed of Dulbecco's Modified Eagle Medium (DMEM, A13169050, Applichem, Darmstadt, Germany) supplemented with 10\% non-inactivated fetal bovine serum (Alfagene, Carcavelos, Portugal), $100 \mathrm{U} / \mathrm{mL}$ penicillin, $100 \mu \mathrm{g} / \mathrm{mL}$ streptomycin, and $17.95 \mathrm{mM}$ sodium bicarbonate, all from Sigma, St. Louis, MO, USA.

Raw 264.7 cells, a mouse leukemic monocyte macrophage cell line from American Type Culture Collection (ATCC TIB-71), were plated $\left(3 \times 10^{5}\right.$ cells/well) and allowed to stabilize for $12 \mathrm{~h}$. Afterwards, the cell medium was replaced, and the cells were pre-incubated with $50 \mu \mathrm{L}$ of pHWE or phosphate buffer with or without (control) $0.1 \%$ DMSO, for $1 \mathrm{~h}$. Raw 264.7 cells were later activated with $1 \mu \mathrm{g} / \mathrm{mL}$ lipopolysaccharide (LPS from Escherichia coli, serotype 026:B6, Sigma Chemical Co., St. Louis, MO, USA) for $24 \mathrm{~h}$. Cell viability was assessed using 3-(4,5-Dimethylthiazol-2-yl)-2,5-diphenyl tetrazolium bromide (MTT, Acros Organics, Geel, Belgium). The NO• production was determined by a colorimetric reaction with the Griess reagent, as previously reported by Búfalo et al. [22].

\subsection{Nutritional Properties of the Yogurt}

Given that apple pomace water extracts display high carbohydrate contents [23], the nutritional properties of the control and the HWE yogurts were evaluated by measuring the total sugar content and the amount of reducing sugars using the phenol-sulfuric method [24] and the 3,5-dinitrosalicylic acid (DNS) method [25]. The results were expressed as lactose equivalents/100 g, as lactose is the main carbohydrate found in dairy products. To complete the data set, moisture and protein contents were determined, as previously described. The protein conversion factor (6.15) estimated for dairy products was used for protein quantification [14]. The ash content was assessed by determining the final residue after incineration at $500{ }^{\circ} \mathrm{C}$ for $3 \mathrm{~h}$. Fat was calculated by difference. The energetic value was calculated (Equation (3)) according to the energetic parameter published by the European Parliament [26]. As water extracts are known to present polysaccharides, their energetic contribution $(2 \mathrm{kcal} / \mathrm{g})$ was also included, assuming that polysaccharides are not affected and are not consumed by lactic acid bacteria during fermentation:

Energy $(\mathrm{kcal})=4 \times(\mathrm{g}$ of protein $+\mathrm{g}$ of reducing sugars $)+9 \times(\mathrm{g}$ of lipids $)$

$+2 \times$ (g of added apple pomace aqueous extract polysaccharides)

\subsection{Statistical Analysis}

All experiments were performed with at least three independent assays being represented as mean \pm standard error of the mean. Data were statistically analyzed by a trial version of GraphPad Prism 6.01 software (OriginLab Corporation, Northampton, MA, USA) by one-way analysis of variance (ANOVA) followed by Tukey's multiple comparison test. A factor of 0.001 was used, unless otherwise stated.

\section{Results}

\subsection{Apple Pomace Extracts}

The industrial apple pomace had a high water-content $(81 \%)$, rendering high perishability to this by-product. Protein comprised $50 \mathrm{~g} / \mathrm{kg}$ of its dry weight, while carbohydrates were the major 
components (720 g/kg dry weight basis) (Table 1). These included the $180 \mathrm{~g} / \mathrm{kg}$ of free sugars, mainly Fru (77 mol \%), and $530 \mathrm{~g} / \mathrm{kg}$ of polysaccharides with Glc (41 mol \%), GalA (19 mol \%), Ara (12 mol \%), Xyl (10 mol \%), and Gal (9 mol \%) being the main sugars. This composition was characteristic of apple polysaccharides and reflects the presence of pectic polysaccharides as soluble dietary fiber and hemicelluloses and cellulose as insoluble dietary fiber [27,28]. Alongside these carbohydrates, polyphenols were also present. Therefore, hot water extraction was performed as it represents a cheap, non-toxic, environmentally friendly extraction procedure and is easily implementable at an industrial scale [5], in contrast to extractions using common organic solvents. To prevent polyphenol oxidation, diluted acetic acid was used [29].

HWE represented 29\% of dry apple pomace and presented $11 \mathrm{~g} / \mathrm{kg}$ of polyphenols (Table 1). This resulted from the co-extraction of carbohydrates $(950 \mathrm{~g} / \mathrm{kg})$ and protein $(13 \mathrm{~g} / \mathrm{kg})$, which accounted for $39 \%$ and $7 \%$ of that initially present in the apple pomace (Figure 1 and Table 1 ). The mass balance indicated that about $3.26 \mathrm{~g}$ GAE of polyphenols per $\mathrm{kg}$ of apple pomace were extracted. These yields were higher than those obtained with water at room temperature (2.6 g/kg of apple pomace) [30], and lower when using methanol $(3.6 \mathrm{~g} / \mathrm{kg}$ of apple pomace) or acetone $(6.48 \mathrm{~g}$ GAE$/ \mathrm{kg}$ of apple pomace) [9]. It is known that polysaccharides may interact with polyphenols, impairing their transfer from the fruit to the water fraction [31]. However, when using methanol and acetone, solvents that are of chaotropic nature, these interactions are disrupted and polyphenols become soluble [32], explaining the higher yields for methanol and acetone.

In order to infer about possible polyphenols-polysaccharides interactions in the HWE, ultrafiltration was performed using a $10 \mathrm{kDa}$ ultrafiltration membrane. This process is based on the principle that apple polyphenols present, on average, a degree of polymerization of 5 [33], they would diffuse along the membrane unless being retained by any interaction phenomenon. According to the data presented in Table 1,11\% of the polyphenols from the HWE remained in the high molecular weight fraction. This fraction accounted for $6.9 \%$ of the apple pomace and was highly rich in polysaccharides (777 g/kg), mostly composed of Ara (35 mol \%), GalA (36 mol \%), and Glc (9 mol \%). Ara and GalA are carbohydrates characteristic of pectic polysaccharides [28] while Glc is generally associated to glucans [23]. Therefore, it is possible to infer that the polyphenols present in the high molecular weight fraction were retained as a result of interactions with pectic polysaccharides and glucan fractions, as reported to occur between wine polyphenols and polysaccharides [34,35]. However, it is feasible that this retention mostly occurred as a result of covalent interactions between polyphenols and polysaccharides, due to the reactions between polyphenol quinones, formed by oxidation reactions and nucleophilic compounds of the cell wall [29]. In such case, polyphenols may establish bridges between different polysaccharide structures yielding chimeric structures [7]. Therefore, it is also possible to infer that some of the polyphenols present in the low molecular weight material $(75 \% \mathrm{w} / \mathrm{w}$ of the HWE) were probably covalently associated to carbohydrates. Sugar analysis of this fraction showed the prevalence of GalA (45 mol \%) and Ara (15 mol \%), thus suggesting that they were associated to pectic oligosaccharides that globally represented $250 \mathrm{~g} / \mathrm{kg}$ of the low molecular weight material. Such complexes are also present in the final extraction residue where polysaccharides represented $595 \mathrm{~g} / \mathrm{kg}$. Given the detection of GalA (13 mol\%), Ara (8 mol\%) and Gal (8 mol\%), Glc (51 mol\%), and $\mathrm{Xyl}(14 \mathrm{~mol} \%)$, it is feasible that in addition to pectic polysaccharides, polyphenols were covalently linked to glucans $[28,36]$. 
Table 1. Yield (\%), monosaccharide (molar\%), carbohydrate (\%), protein (\%), and polyphenolic composition (g gallic acid equivalents (GAE)/kg) of industrial apple pomace, hot water extract (HWE), high molecular weight material (HMWM), low molecular weight material (LMWM), and extraction residue.

\begin{tabular}{|c|c|c|c|c|c|c|c|c|c|c|c|c|c|c|c|c|}
\hline \multirow{2}{*}{ Fractions } & \multirow{2}{*}{ Yield (\%) } & \multirow{2}{*}{$\begin{array}{c}\text { Yield of } \\
\text { Carbohydrate (\%) }\end{array}$} & & \multicolumn{9}{|c|}{ Carbohydrate (mol\%) } & \multirow{2}{*}{\multicolumn{2}{|c|}{ Total Carbohydrate (\%) }} & \multirow{2}{*}{$\begin{array}{c}\text { Total Protein } \\
\text { (\%) }\end{array}$} & \multirow{2}{*}{$\begin{array}{c}\text { Total PC } \\
\text { (g GAE/kg) }\end{array}$} \\
\hline & & & & Rha & Fuc & Ara & Xyl & Man & Gal & Glc & Fru & GalA & & & & \\
\hline \multirow{2}{*}{$\begin{array}{c}\text { Apple } \\
\text { pomace }\end{array}$} & & & Polysaccharides & 1 & 1 & 12 & 10 & 5 & 9 & 41 & & 19 & 53.4 & \multirow{2}{*}{71.7} & \multirow{2}{*}{5.2} & \multirow{2}{*}{ ND } \\
\hline & & & Free Sugars & & & & & & & 23 & 77 & & 18.3 & & & \\
\hline \multirow{2}{*}{ HWE } & \multirow{2}{*}{29.6} & \multirow{2}{*}{39.2} & Polysaccharides & 3 & 1 & 25 & 3 & & 10 & 9 & & 50 & 42.9 & \multirow{2}{*}{94.9} & \multirow{2}{*}{1.3} & \multirow{2}{*}{11} \\
\hline & & & Free Sugars & & & & & & & 18 & 82 & & 52.0 & & & \\
\hline HMWM & 6.9 & 7.5 & Polysaccharides & 1 & $\mathrm{t}$ & 35 & 6 & 1 & 10 & 9 & & 36 & 77.7 & 77.7 & ND & 5 \\
\hline \multirow{2}{*}{ LMWM } & \multirow{2}{*}{22.3} & \multirow{2}{*}{27.7} & Polysaccharides & 1 & $\mathrm{t}$ & 15 & 2 & & 6 & 34 & & 42 & 33.5 & \multirow{2}{*}{89.0} & \multirow{2}{*}{ ND } & \multirow{2}{*}{9} \\
\hline & & & Free Sugars & & & & & & & 6 & 94 & & 55.5 & & & \\
\hline Residue & 67.4 & 55.9 & Polysaccharides & 1 & 1 & 8 & 14 & 4 & 8 & 51 & & 13 & 59.5 & 59.5 & 7.1 & \\
\hline
\end{tabular}

$\mathrm{t}=$ trace; $\mathrm{ND}=$ not determined 
To better understand the nature of the polyphenols and their bioactivity, the HWE was subjected to solid-phase extraction based on the principle that polyphenols, which have hydrophobic character, would be retained on the C18 cartridge while carbohydrates, which are hydrophilic molecules, would elute from the cartridge. The hydrophobic fraction, named pHWE, corresponded to $1.6 \%$ of the dry apple pomace. According to Folin-Ciocalteu's method, polyphenols represent $149 \mathrm{~g} / \mathrm{kg}$ and accounted for $63 \%$ of those in the HWE. The remaining 37\% of the polyphenols eluted from the cartridge alongside with the HWE carbohydrates. These probably have the contribution of free sugars, which are known to have a reducing capacity and therefore interfere in the Folin-Ciocalteu method. However, the hypothesis that polyphenolic structures exist in this fraction as a result of covalent bonding to polysaccharides should not be discarded.

UHPLC-DAD-ESI-MS $^{n}$ analysis showed that the pHWE was mainly composed of flavonols (Table 2) which included quercetin-3-O-galactoside (27\%), quercetin-3-O-rhamnoside $(23 \%)$, quercetin 3-O-arabinofuranoside $(13 \%)$, and the dihydrochalcone phloretin-2-O-glucoside (14\%). Quercetin-3-O-xylanoside (8\%), quercetin-3-O-glucoside (7\%), quercetin-O-pentoside (3\%), quercetin-3-O-rutinoside (3\%), and quercetin 3-O-arabinopyranoside (2\%) were also detected as minor compounds, which was in agreement with previously reported work concerning the polyphenolic composition of apple pomace $[5,37]$. However, this analysis only explained $77 \%$ (115 mg/g of extract) of the polyphenols detected by the Folin-Ciocalteu method (149 mg/g of extract). According to Millet et al. [38], this difference, together with the fact that only $11 \%$ of the extract composition was explained, is highly suggestive of the occurrence of polyphenol oxidation products formed during apple processing [39]. Oxidation products of polyphenols are formed in very low amounts and present newly formed linkages [40], hardly quantitative by common ultra-high-pressure liquid chromatography (UHPLC) techniques [41]. These include hydroxycinnamic acid, dihydrochlacones, and flavan-3-ols oxidations products, already shown to be present in apple pomace [8].

Table 2. Retention time (RT), mass spectrum (MS), and polyphenolic composition (mg/g of extract) of pHWE.

\begin{tabular}{|c|c|c|c|c|c|c|}
\hline \multirow{2}{*}{$\mathbf{N}^{\circ}$} & \multirow{2}{*}{ RT } & \multirow{2}{*}{ Compound } & \multirow{2}{*}{$\lambda_{\max }$} & \multirow{2}{*}{$\operatorname{MS}(m / z)$} & \multirow{2}{*}{$\operatorname{MS}^{2}(m / z)$} & \multirow{2}{*}{$\begin{array}{l}\text { Extract } \\
\text { pHWE }\end{array}$} \\
\hline & & & & & & \\
\hline 1 & 12.3 & Quercetin-3-O-rutinoside $^{a}$ & 254,353 & 609 & 463,301 & $3.27 \pm 0.06$ \\
\hline 2 & 12.6 & Quercetin-3-O-galactoside $^{b}$ & 256,354 & 463 & 301 & $31.37 \pm 0.32$ \\
\hline 3 & 12.7 & Quercetin-3-O-glucoside ${ }^{\text {a }}$ & 256,353 & 463 & 301 & $8.45 \pm 0.10$ \\
\hline 4 & 13.2 & Quercetin-3-O-xylanoside $^{b}$ & 256,354 & 433 & 301 & $8.88 \pm 0.10$ \\
\hline 5 & 13.4 & Quercetin 3-O-arabinopyranoside ${ }^{\mathrm{b}}$ & 243,352 & 433 & 301 & $2.31 \pm 0.04$ \\
\hline 6 & 13.5 & Quercetin 3-O-arabinofuranoside ${ }^{b}$ & 256,352 & 433 & 301 & $15.09 \pm 0.16$ \\
\hline 7 & 13.7 & Quercetin-O-pentoside $^{\mathrm{b}}$ & 256,351 & 433 & 301 & $3.32 \pm 0.05$ \\
\hline 8 & 13.8 & Quercetin-3-O-rhamnoside ${ }^{b}$ & 256,350 & 447 & 301 & $26.05 \pm 0.27$ \\
\hline \multirow[t]{2}{*}{9} & 14.9 & Phloretin-2-O-glucoside ${ }^{\text {a }}$ & 227,284 & 435 & 273 & $15.96 \pm 0.20$ \\
\hline & & & & & Total & $114.75 \pm 1.25$ \\
\hline
\end{tabular}

Identification was performed based on (a) the corresponding standard; (b) UV and MS ${ }^{\mathrm{n}}$ spectra, plus elution order previously described in the literature $[5,37]$.

\subsection{Antioxidant and Anti-Inflammatory Potential}

To provide evidence of the antioxidant potential of aqueous extracts from apple pomace, two widespread chemical models, the DPPH• and ABTS ${ }^{+}$radical inhibition assays, were used. As represented in Table 3, the $\mathrm{EC}_{50}$ values of the HWE for the DPPH• and ABTS $\bullet^{+}$methods were 1.34 and $0.53 \mathrm{mg} / \mathrm{mL}$, respectively. The increment of polyphenols in the purified fraction (pHWE) was reflected on the extract's antioxidant activity, which exhibited DPPH• and ABTS $\bullet^{+} \mathrm{EC}_{50}$ of 82.4 and $35.2 \mu \mathrm{g} / \mathrm{mL}$, respectively (Table 3). When expressing the antioxidant activity with reference to total 
polyphenols (Table 3), it was observed that pHWE accounted for $92 \%$ of the HWE antioxidant activity. These results suggested that most of the compounds responsible for the antioxidant properties of the HWE were recovered after purification using $\mathrm{C} 18$ cartridges. The pHWE also presented the capability to inhibit the formation of $\mathrm{OH} \bullet$ ( 6.75 mannitol equivalents/g of extract) generated by Fenton reactions from a ferric-ascorbate-EDTA- $\mathrm{H}_{2} \mathrm{O}_{2}$ system [20]. This can be attributed to both iron chelation and direct scavenging of $\mathrm{OH} \bullet$ by polyphenols. However, in contrast to DPPH• and ABTS $\bullet^{+}$which are not biological radicals, $\mathrm{OH} \bullet$ is present in biological systems, resulting from Fenton reactions and cellular processes such as cell respiration and inflammation, prone to damage cellular lipids, proteins, and nucleic acids [42]. Closer extrapolations to in vivo effects could be inferred when complementing with other radical generating systems, either using enzymes such as xanthine/xanthine oxidase or cellular models such as activated neutrophils [43].

Nitric oxide (NO•) has been recognized as a versatile player in several biological mechanisms, including endothelial cell function and inflammation, turning it into a biomarker in the screening of new anti-hypertensive and anti-inflammatory drugs [44]. Therefore, the potential capability of the aqueous extracts from apple pomace to regulate $\mathrm{NO} \bullet$-driven processes was inferred through its ability to scavenge chemically generated NO•. As represented in Table 3, at a concentration of $130 \mu \mathrm{g} / \mathrm{mL}$, the pHWE inhibited $35 \%$ of the NO• chemically generated, which is in accordance with the antioxidant properties previously described in this work. This inhibition was, however, lower than that produced by ascorbic acid $(57 \%)$.

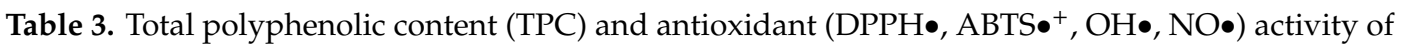
the hot water extract before (HWE) and after the purification (pHWE).

\begin{tabular}{|c|c|c|c|c|c|}
\hline Extract & TPC & DPPH• & ABTS•+ & $\mathrm{OH} \bullet$ & NO• \\
\hline HWE & $10.7 \pm 0.2$ & $1339 \pm 211(14.2 \pm 1.7)$ & $532 \pm 11.5(5.69 \pm 0.12)$ & - & - \\
\hline pHWE & $149 \pm 1.87$ & $82.4 \pm 11.2(12.3 \pm 1.7)$ & $35.2 \pm 5.9(5.23 \pm 0.44)$ & $6.75 \pm 0.45$ & $35.2 \pm 5.9$ \\
\hline AA & - & $2.70 \pm 0.30$ & $2.68 \pm 0.03$ & - & $57.3 \pm 2.3$ \\
\hline
\end{tabular}

The first and second values for the DPPH $\bullet$ and ABTS $\bullet{ }^{+}$are expressed in terms of $\mathrm{EC}_{50}(\mu \mathrm{g}$ of extract $/ \mathrm{mL})$ and as relative antioxidant capacity with reference to total polyphenols ( $\mu \mathrm{g}$ GAE of extract $/ \mathrm{mL}$ ), respectively. $\mathrm{OH} \bullet$ scavenging was expressed as mannitol equivalents (mmol/g of extract), and for the NO• method as percentage of inhibition at $130 \mu \mathrm{g} / \mathrm{mL}$. Values are compared to ascorbic acid (AA).

To provide closer evidence of anti-inflammatory effects occurring in vivo, which could potentiate the valuation of apple pomace for the development of functional foods, the pHWE was tested on LPS-stimulated Raw 264.7 cells, by measuring their effect on the accumulation of nitrites in the culture medium, an indicator of $\mathrm{NO}^{\bullet}$ production. Indeed, macrophages activated by the Toll-like receptor 4 (TLR4) agonist LPS, produce large amounts of $\mathrm{NO} \bullet$ and constitute a well-described in vitro model of inflammation, useful for the screening of molecules with anti-inflammatory activity [44]. In a first approach, the occurrence of possible cytotoxic effects triggered by the pHWE was evaluated by determining the cellular viability of Raw 264.7 macrophages, stimulated with LPS (Figure 2a). The presence of $0.1 \%$ DMSO did not affect the cell viability which was similar $(p>0.05)$ to the control in all tested concentrations. Accordingly, previously reported data showed that pure quercetin-glycosylated derivatives and phloridzin are not cytotoxic for the corresponding concentrations herein tested, as evaluated in similar cell models [45,46].

The anti-inflammatory potential of the pHWE was measured by the reduction of nitrite accumulated in the culture medium in comparison with the amount released by untreated LPS-stimulated Raw 264.7 cells. When treated with LPS, NO• released into the culture medium by macrophages increased from the basal value of $0.2 \mu \mathrm{M}$ to $22 \mu \mathrm{M}$. Yet, when pre-incubated with pHWE in all non-cytotoxic concentrations $(280,375,745$, and $1490 \mu \mathrm{g} / \mathrm{mL})$, the NO• released by macrophages was limited to $26 \%-84 \%$ of the value observed for non-treated cells (Figure $2 \mathrm{~b}$ ) in a concentration-dependent manner. 
a)

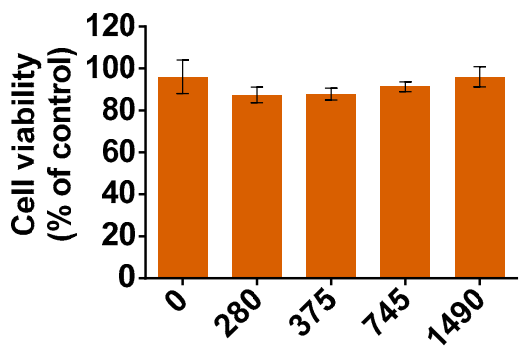

Concentration of pHWE extract $(\mu \mathrm{g} / \mathrm{mL})$ b)

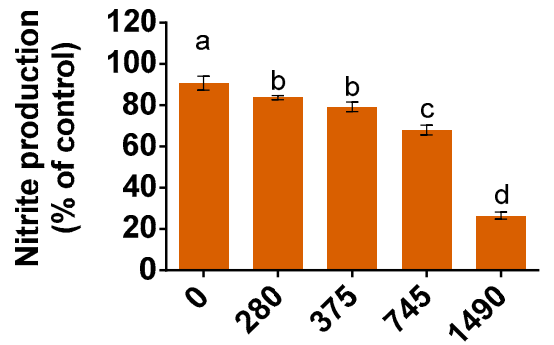

Concentration of pHWE extract $(\mu \mathrm{g} / \mathrm{mL})$

Figure 2. Treatment of mouse macrophage cell line, Raw 264.7, with apple pomace extracts, followed by incubation with lipopolysaccharide (LPS) from Escherichia coli as in vitro model of inflammation. (a) Cell viability (\% of the control) of Raw 264.7 cells after incubation with polyphenolic-rich hot water extract (pHWE) at 0-1490 $\mathrm{gg} / \mathrm{mL}$ in phosphate buffer/dimethyl sulfoxide (DMSO) (99.9:0.01; v/v). (b) Inhibitory effect of pHWE on LPS-induced nitrite production (\% of the control) in Raw 264.7 cells. Data represent mean \pm standard deviation of 3 independent assays. Different letters indicate statistical significance between pHWE concentrations $(\mathrm{a}, \mathrm{b}, \mathrm{c}$, and $\mathrm{d}, p<0.001)$ compared to control by one-way ANOVA followed by Tukey's Multiple comparison test.

Some of the major polyphenols present in the apple pomace aqueous extracts have been previously reported to possess anti-inflammatory properties. For example, quercetin, a flavonol, and some of its glycosylated derivatives were shown to inhibit NO• production in LPS-induced Raw 264.7 cells and to modulate several inflammatory signaling cascades [31,33]. Phloridzin, a dihydrochalchone, has also been described to modulate inflammatory responses [32]. Nevertheless, direct relation of the observed anti-inflammatory effect with the presence of polyphenols is still not possible to establish, since despite pHWE purification, other unknown compounds representing $85 \%$ of the extract, possibly apple polyphenol oxidation products formed during processing [29], may also be responsible for the effects. Furthermore, no comparisons with the HWE could be established given its poor solubility in phosphate-buffered saline with $2 \%(\mathrm{v} / \mathrm{v})$ dimethyl sulfoxide (DMSO) at room temperature and the adverse effects on the viability of Raw 264.7 cells when using higher concentrations of DMSO. Although a deeper consolidation through the measurement of pro- and anti-inflammatory interleukins and/or other anti-inflammatory markers is required, these results evidence the possible valuation of apple pomace as a potential anti-inflammatory nutraceutical.

\subsection{Application as a Food Ingredient in Yogurt Formulation}

Given the presence of polysaccharide/polyphenol complexes and the possible antioxidant and anti-inflammatory properties that could be attributed to apple pomace extracts, their potential to be used as ingredients for food formulations was tested. Yoghurt was chosen as it is a worldwide, ready-to-eat product with a high nutritional value and positive bioactive effects that can be reinforced by the addition of other components [47-49]. As a result, HWE was incorporated into yogurt formulations to reach $3.3 \%\left(\mathrm{w}_{\text {extract }} / \mathrm{w}_{\text {milk }}\right)$. The incorporation of the HWE resulted in a mixture with an initial $\mathrm{pH}$ of 5.34, 19\% lower than the control (6.56), which is in accordance with the higher titratable acidity observed ( 0.361 versus $0.097 \mathrm{~g}$ lactic acid/100 g of yogurt) (Figure $3 \mathrm{a}, \mathrm{b}$ ). This effect was similarly observed when adding wine grape pomace to yogurts [47] and could be related to naturally occurring organic acids, such as malic acid, in apple pomace. The similar number of Streptococcus thermophilus counts (6.4 Log CFU/g of yogurt) observed in both yogurts (Figure 3c) is indicative that the viability of lactic acid bacteria is not affected by the supplementation. As represented in Figure $3 \mathrm{~d}$, the total polyphenolic content of the control yogurt $(11 \pm 2.0 \mathrm{mg}$ GAE/100 $\mathrm{g}$ of fresh weight yogurt), whose activity can also be attributed to Tyr, Trp and Phe [48], more than doubled with the addition of the extract $(29 \pm 3.0 \mathrm{mg} \mathrm{GAE} / 100 \mathrm{~g}$ of fresh weight yogurt). This represented a higher phenolic content compared to the use of hazelnut skins [49], but inferior when supplementing yogurts with wine grape pomace [47]. These results are attributed to differences at quantitative and qualitative levels 
of the phenolic structures present in the various agro-industrial by-products. When compared to the total polyphenols added to the yogurt mixture (32.1 mg GAE) with the amount determined in the yogurt mixture after control subtraction, it was observed that only $56 \%$ were determined by the Folin-Ciocalteu method, similar to what was observed when protein was added to polyphenols [50]. This variation is possibly attributed to the capability of apple pomace polyphenols to interact with milk proteins, thereby blocking the polyphenolic aromatic rings responsible for their antioxidant properties. Nevertheless, an increase of the antioxidant activity in more than three-fold (from $9 \pm 1$ to $32 \pm 4 \mathrm{mg}$ trolox/100 g of fresh weight yogurt) was measured by the ABTS $\bullet^{+}$method (Figure 1e), reflecting the antioxidant properties described for the HWE.

a)

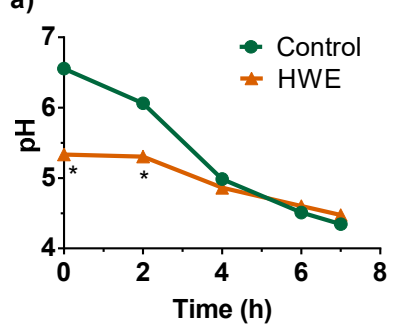

c)

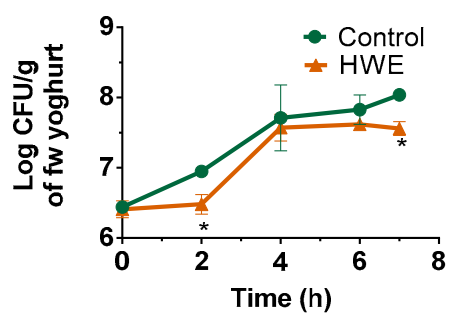

d) b)

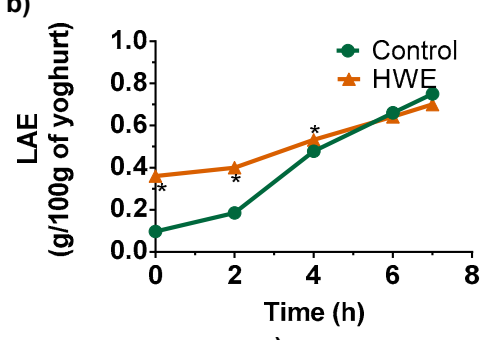

e)

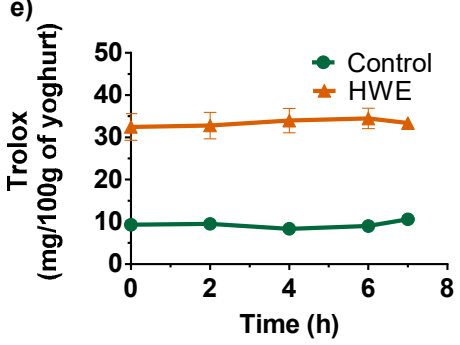

Figure 3. Evolution of (a) $\mathrm{pH}$, (b) titratable acidity (expressed as lactic acid equivalents (LAE)/100 g of fresh weight yogurt)), (c) Streptococcus thermophilus counts (Log CFU/g of fresh weight yogurt), (d) total polyphenolic content (mg gallic acid equivalents (GAE)/100 g of fresh weight yogurt), and (e) antioxidant activity (mg of Trolox/100 $\mathrm{g}$ of fresh weight yogurt) along the fermentation process for the control and supplemented yogurt with the HWE.

As represented in Figure $3 \mathrm{a}-\mathrm{c}$ the $\mathrm{pH}$ decrease, concomitant with the increase of the titratable acidity and $S$. thermophilus counts, demonstrated that the mixtures with and without apple pomace HWE were fermented, yielding a control and a supplemented yogurt. Nevertheless, S. thermophilus in the HWE yogurt appeared to have an increased lag phase and reached lower counts at the end of fermentation when compared to the control, which might indicate that the tested concentration may have an inhibitory effect on their growth. Although lactic acid bacteria are generally isolated and remain viable in acidic foods, their growth is inhibited at low $\mathrm{pH}$ levels, in particular the growth of S. thermophilus [51]. Therefore, it is possible that the extended lag phase observed in the HWE yogurt resulted from its initial acidic $\mathrm{pH}$ when compared to the one observed for the control. Nevertheless, the $S$. thermophilus counts exceeded the $7 \mathrm{Log} \mathrm{CFU} / \mathrm{g}$, with a final $\mathrm{pH}$ below 4.5 , which are positive critical factors to inhibit pathogenic microorganisms such as Listeria monocytogenes, Salmonella, or Escherichia coli, and to assure the stability of the product [52,53]. Furthermore, it was observed that the yogurt total polyphenolic content and antioxidant activity (Figure 3d,e) remained unchanged during the fermentation process. This suggested that the polyphenols incorporated into yogurt were not affected. However, given the capability of bacteria to metabolize polyphenols, it is feasible that some apple pomace polyphenolic structures were converted to metabolites that still possess antioxidant properties. These changes might not be reflected on the overall total phenolic content and antioxidant activity, as measured by the Folin-Ciocalteu and ABTS $\bullet^{+}$methods. Reports on yogurts supplemented with hazelnut skins [49] and grape pomace [47] suggest that their antioxidant properties can be relatively stable for at least two weeks. 
Table 4 shows the nutritional composition, expressed in $\mathrm{g} / 100 \mathrm{~g}$ of fresh weight yogurt, and the energetic value, expressed in $\mathrm{kcal} / 100 \mathrm{~g}$ of fresh weight yogurt of the control and supplemented yogurt. The nutritional analysis revealed that water was the major component $(87 \%-89 \%)$ in both formulations. The addition of the HWE resulted in an increase of the yogurts total sugars from $5.5 \%$ to $7.3 \%$ and of the reducing sugars from $4.5 \%$ to $5.1 \%$. As lactic acid bacteria, particularly S. thermophilus, preferentially use lactose over glucose [54], these increments can be attributed to some glucose and fructose and to oligosaccharides and polysaccharides from the HWE that remain after fermentation. From the latter, two distinct groups could be highlighted: (1) high molecular weight (>10 kDa) polysaccharide/polyphenol complexes to which higher short-chain fatty acid production and polyphenol-derived metabolites are attributed than to polyphenols and polysaccharides alone [55], and (2) pectic oligosaccharides to which prebiotic properties are also attributed [56]. It has been shown that these carbohydrate structures also improve yogurt firmness [57]. Protein, fat, and ash corresponded to about $3.2 \%, 1.5 \%$, and $0.9 \%$, respectively. Overall, the energetic values of both yogurts were 47 and $49 \mathrm{kcal} / 100 \mathrm{~g}$ of fresh weight for the control and HWE yogurt, respectively.

Table 4. Nutritional composition expressed as $\mathrm{g} / 100 \mathrm{~g}$ of fresh weight control and supplemented yogurt with apple pomace HWE.

\begin{tabular}{ccc}
\hline Components & Control & HWE \\
\hline Moisture & $88.8 \pm 0.0$ & $87.2 \pm 0.1$ \\
Total Sugars & $5.45 \pm 0.12$ & $7.30 \pm 0.18$ \\
Reducing Sugars & $4.49 \pm 0.10$ & $5.05 \pm 0.04$ \\
HWE polysaccharides * & & $1.43 \pm 0.01$ \\
Protein & $3.32 \pm 0.04$ & $3.21 \pm 0.08$ \\
Fat & $1.68 \pm 0.15$ & $1.46 \pm 0.07$ \\
Ash & $0.75 \pm 0.01$ & $0.84 \pm 0.01$ \\
Energetic (kcal) & $46.5 \pm 1.1$ & $49.1 \pm 0.7$ \\
\hline
\end{tabular}

* Assuming that HWE polysaccharides are preserved during fermentation.

\section{Conclusions}

In this work, it was shown that by hot water extraction under acidic conditions more than $3 \mathrm{~g} / \mathrm{kg}$ of dry apple pomace could be obtained. Ultrafiltration demonstrated that in addition to apple native polyphenols, some phenolic structures were probably attached to the high molecular weight material (>10 kDa). Separation of HWE polyphenols by solid-phase extraction allowed us to infer the potential antioxidant and anti-inflammatory capacities, as shown by their scavenging ability towards NO• in chemical and cellular models. When applied to yogurt formulations, apple pomace HWE allowed for achieving a final product with improved fiber content and antioxidant properties when compared to the plain yogurt. However, as this study involves only in vitro assays, its extrapolation to humans cannot be done. This results from the fact that DPPH• and ABTS $\bullet+$ radicals, although suggestive of antioxidant properties, do not represent physiological radicals while the $\mathrm{OH} \bullet$ and NO• scavenging assays were performed using in vitro models. Therefore, these results should be considered as a proof of concept for food chemists and industrials. For the evaluation of possible health benefits, in vivo studies addressing the bioavailability of the polyphenols and the dosage required to observe any antioxidant or anti-inflammatory effects are necessary. In fact, these requirements are regulated by the European Food Safety Authority (EFSA) and must meet not only the requirements for health claims (Regulation (EC) No 1924/2006 of the European Parliament and of the Council), but also for safety (Regulation (EU) No 1169/2011 of the European Parliament and of the Council of 25 October 2011) before any commercialization of a food product stating health benefits. In this context, no statement of the type "antioxidant and anti-inflammatory apple pomace extract/yoghurt" cannot be used at this stage and any commercial exploitation of the developed yoghurt formulation must naturally assure its safety. 
Author Contributions: P.A.R.F. contributed to conceptualization, investigation, data curation, and writing the original draft. S.S.F. and R.B. contributed to conceptualization, investigation, data curation, and writing reviewing and editing. I.F. and M.T.C. contributed to conceptualization, investigation, resources and writing - reviewing and editing. A.P. contributed to conceptualization, investigation, and writing - reviewing and editing. C.P.P. contributed to methodology, resources, and writing - reviewing and editing. E.C. contributed to conceptualization, methodology, supervision, and writing - reviewing and editing. M.A.C. contributed to conceptualization, investigation, methodology, supervision, and writing - reviewing and editing. S.M.C. contributed to conceptualization, investigation, methodology, supervision, and writing - reviewing and editing. D.F.W. contributed to conceptualization, investigation, methodology, supervision, writing - reviewing and editing, and project administration.

Funding: Thanks are due to the University of Aveiro and FCT/MCT for the financial support for the QOPNA research Unit (FCT UID/QUI/00062/2019) and to CITAB research Unit (FCT UID/AGR/04033/2019) through national funds and, where applicable, co-financed by the FEDER, within the PT2020 Partnership Agreement, and to the Portuguese NMR Network. Pedro A. R. Fernandes (SFRH/BD/107731/2015) and Elisabete Coelho (SFRH/BPD/70589/2010) were supported by FCT/MEC grants. Claudia Passos acknowledges FCT (CEECIND/01873/2017) contract. Susana M. Cardoso thanks the research contract under the project AgroForWealth: Biorefining of agricultural and forest by-products and wastes: integrated strategic for valorisation of resources towards society wealth and sustainability (CENTRO-01-0145-FEDER-000001), funded by Centro2020, through FEDER and PT2020. Thanks are due to Indumape for providing the apple pomace and to project Profitapple 3862.

Conflicts of Interest: The authors declare no conflict of interest.

\section{References}

1. O'Shea, N.; Arendt, E.K.; Gallagher, E. Dietary fibre and phytochemical characteristics of fruit and vegetable by-products and their recent applications as novel ingredients in food products. Innov. Food Sci. Emerg. Technol. 2012, 16, 1-10. [CrossRef]

2. Rabetafika, H.N.; Bchir, B.; Blecker, C.; Richel, A. Fractionation of apple by-products as source of new ingredients: Current situation and perspectives. Trends Food Sci. Technol. 2014, 40, 99-114. [CrossRef]

3. Boyer, J.; Liu, R.H. Apple phytochemicals and their health benefits. Nutr. J. 2004, 3, 5. [CrossRef] [PubMed]

4. Mirabella, N.; Castellani, V.; Sala, S. Current options for the valorization of food manufacturing waste: A review. J. Clean. Prod. 2014, 65, 28-41. [CrossRef]

5. Çam, M.; Aaby, K. Optimization of Extraction of Apple Pomace Phenolics with Water by Response Surface Methodology. J. Agric. Food Chem. 2010, 58, 9103-9111. [CrossRef] [PubMed]

6. Kschonsek, J.; Wolfram, T.; Stöckl, A.; Böhm, V. Polyphenolic Compounds Analysis of Old and New Apple Cultivars and Contribution of Polyphenolic Profile to the In Vitro Antioxidant Capacity. Antioxidants 2018, 7, 20. [CrossRef] [PubMed]

7. Le Bourvellec, C.; Guyot, S.; Renard, C.M.G.C. Interactions between apple (Malus x domestica Borkh.) polyphenols and cell walls modulate the extractability of polysaccharides. Carbohydr. Polym. 2009, 75, 251-261. [CrossRef]

8. Fernandes, P.A.R.; Le Bourvellec, C.; Renard, C.M.G.C.; Nunes, F.M.; Bastos, R.; Coelho, E.; Wessel, D.F.; Coimbra, M.A.; Cardoso, S.M. Revisiting the chemistry of apple pomace polyphenols. Food Chem. 2019. [CrossRef] [PubMed]

9. Suárez, B.; Álvarez, Á.L.; García, Y.D.; del Barrio, G.; Lobo, A.P.; Parra, F. Phenolic profiles, antioxidant activity and in vitro antiviral properties of apple pomace. Food Chem. 2010, 120, 339-342. [CrossRef]

10. Kennedy, M.; List, D.; Lu, Y.; Foo, L.Y.; Newman, R.H.; Sims, I.M.; Bain, P.J.S.; Hamilton, B.; Fenton, G. Apple Pomace and Products Derived from Apple Pomace: Uses, Composition and Analysis. In Analysis of Plant Waste Materials; Linskens, H.F., Jackson, J.F., Eds.; Springer: Berlin/Heidelberg, Germany, 1999; pp. 75-119.

11. Rohn, S.; Buchner, N.; Driemel, G.; Rauser, M.; Kroh, L.W. Thermal Degradation of Onion Quercetin Glucosides under Roasting Conditions. J. Agric. Food Chem. 2007, 55, 1568-1573. [CrossRef]

12. Le Bourvellec, C.; Gouble, B.; Bureau, S.; Loonis, M.; Plé, Y.; Renard, C.M.G.C. Pink Discoloration of Canned Pears: Role of Procyanidin Chemical Depolymerization and Procyanidin/Cell Wall Interactions. J. Agric. Food Chem. 2013, 61, 6679-6692. [CrossRef] [PubMed]

13. Passos, C.P.; Ferreira, S.S.; Serôdio, A.; Basil, E.; Marková, L.; Kukurová, K.; Ciesarová, Z.; Coimbra, M.A. Pectic polysaccharides as an acrylamide mitigation strategy-Competition between reducing sugars and sugar acids. Food Hydrocoll. 2018, 81, 113-119. [CrossRef] 
14. Sosulski, F.W.; Imafidon, G.I. Amino acid composition and nitrogen-to-protein conversion factors for animal and plant foods. J. Agric. Food Chem. 1990, 38, 1351-1356. [CrossRef]

15. Blumenkrantz, N.; Asboe-Hansen, G. New method for quantitative determination of uronic acids. Anal. Biochem. 1973, 54, 484-489. [CrossRef]

16. Brunton, N.P.; Gormley, T.R.; Murray, B. Use of the alditol acetate derivatisation for the analysis of reducing sugars in potato tubers. Food Chem. 2007, 104, 398-402. [CrossRef]

17. Singleton, V.L.; Rossi, J.A. Colorimetry of Total Phenolics with Phosphomolybdic-Phosphotungstic Acid Reagents. Am. J. Enol. Viticult. 1965, 16, 144.

18. Brand-Williams, W.; Cuvelier, M.E.; Berset, C. Use of a free radical method to evaluate antioxidant activity. LWT Food Sci. Technol. 1995, 28, 25-30. [CrossRef]

19. Re, R.; Pellegrini, N.; Proteggente, A.; Pannala, A.; Yang, M.; Rice-Evans, C. Antioxidant activity applying an improved ABTS radical cation decolorization assay. Free Radic. Biol. Med. 1999, 26, 1231-1237. [CrossRef]

20. Kunchandy, E.; Rao, M.N.A. Oxygen radical scavenging activity of curcumin. Int. J. Pharm. 1990, 58, 237-240. [CrossRef]

21. Catarino, M.D.; Silva, A.M.S.; Cruz, M.T.; Cardoso, S.M. Antioxidant and anti-inflammatory activities of Geranium robertianum L. decoctions. Food Funct. 2017, 8, 3355-3365. [CrossRef]

22. Búfalo, M.C.; Ferreira, I.; Costa, G.; Francisco, V.; Liberal, J.; Cruz, M.T.; Lopes, M.C.; Batista, M.T.; Sforcin, J.M. Propolis and its constituent caffeic acid suppress LPS-stimulated pro-inflammatory response by blocking NF-kB and MAPK activation in macrophages. J. Ethnopharmacol. 2013, 149, 84-92. [CrossRef] [PubMed]

23. Renard, C.M.G.C.; Lemeunier, C.; Thibault, J.F. Alkaline extraction of xyloglucan from depectinised apple pomace: Optimisation and characterisation. Carbohydr. Polym. 1995, 28, 209-216. [CrossRef]

24. DuBois, M.; Gilles, K.A.; Hamilton, J.K.; Rebers, P.t.; Smith, F. Colorimetric method for determination of sugars and related substances. Anal. Chem. 1956, 28, 350-356. [CrossRef]

25. Miller, G.L. Use of dinitrosalicylic acid reagent for determination of reducing sugar. Anal. chem. 1959, 31, 426-428. [CrossRef]

26. European Parliament. The Council of the European Union. Regulation (EU) No 1169/2011. Off. J. Eur. Union 2011, L 304, 18-63.

27. Percy, A.E.; Melton, L.D.; Jameson, P.E. Xyloglucan and hemicelluloses in the cell wall during apple fruit development and ripening. Plant Sci. 1997, 125, 31-39. [CrossRef]

28. Renard, C.M.G.C.; Voragen, A.G.J.; Thibault, J.F.; Pilnik, W. Studies on apple protopectin V: Structural studies on enzymatically extracted pectins. Carbohydr. Polym. 1991, 16, 137-154. [CrossRef]

29. Ferreira, D.; Guyot, S.; Marnet, N.; Delgadillo, I.; Renard, C.M.G.C.; Coimbra, M.A. Composition of Phenolic Compounds in a Portuguese Pear (Pyrus communis L. Var. S. Bartolomeu) and Changes after Sun-Drying. J. Agric. Food Chem. 2002, 50, 4537-4544. [CrossRef] [PubMed]

30. Reis, S.F.; Rai, D.K.; Abu-Ghannam, N. Water at room temperature as a solvent for the extraction of apple pomace phenolic compounds. Food Chem. 2012, 135, 1991-1998. [CrossRef]

31. Guyot, S.; Marnet, N.; Sanoner, P.; Drilleau, J.-F. Variability of the Polyphenolic Composition of Cider Apple (Malus domestica) Fruits and Juices. J. Agric. Food Chem. 2003, 51, 6240-6247. [CrossRef]

32. Renard, C.M.G.C.; Baron, A.; Guyot, S.; Drilleau, J.F. Interactions between apple cell walls and native apple polyphenols: Quantification and some consequences. Int. J. Biol. Macromol. 2001, 29, 115-125. [CrossRef]

33. Guyot, S.; Le Bourvellec, C.; Marnet, N.; Drilleau, J.F. Procyanidins are the most Abundant Polyphenols in Dessert Apples at Maturity. LWT Food Sci. Technol. 2002, 35, 289-291. [CrossRef]

34. Gonçalves, F.J.; Rocha, S.M.; Coimbra, M.A. Study of the retention capacity of anthocyanins by wine polymeric material. Food Chem. 2012, 134, 957-963. [CrossRef] [PubMed]

35. Gonçalves, F.J.; Fernandes, P.A.R.; Wessel, D.F.; Cardoso, S.M.; Rocha, S.M.; Coimbra, M.A. Interaction of wine mannoproteins and arabinogalactans with anthocyanins. Food Chem. 2018, 243, 1-10. [CrossRef] [PubMed]

36. Cruz, M.G.; Bastos, R.; Pinto, M.; Ferreira, J.M.; Santos, J.F.; Wessel, D.F.; Coelho, E.; Coimbra, M.A. Waste mitigation: From an effluent of apple juice concentrate industry to a valuable ingredient for food and feed applications. J. Clean. Prod. 2018. [CrossRef]

37. Sánchez-Rabaneda, F.; Jáuregui, O.; Lamuela-Raventós, R.M.; Viladomat, F.; Bastida, J.; Codina, C. Qualitative analysis of phenolic compounds in apple pomace using liquid chromatography coupled to mass spectrometry in tandem mode. Rapid Commun. Mass Spectrom. 2004, 18, 553-563. [CrossRef] 
38. Millet, M.; Poupard, P.; Le Quéré, J.-M.; Bauduin, R.; Guyot, S. Haze in Apple-Based Beverages: Detailed Polyphenol, Polysaccharide, Protein, and Mineral Compositions. J. Agric. Food Chem. 2017, 65, 6404-6414. [CrossRef]

39. Nicolas, J.J.; Richard-Forget, F.C.; Goupy, P.M.; Amiot, M.J.; Aubert, S.Y. Enzymatic browning reactions in apple and apple products. Crit. Rev. Food Sci. Nutr. 1994, 34, 109-157. [CrossRef]

40. Bernillon, S.; Guyot, S.; Renard, C.M.G.C. Detection of phenolic oxidation products in cider apple juice by high-performance liquid chromatography electrospray ionisation ion trap mass spectrometry. Rapid Commun. Mass Spectrom. 2004, 18, 939-943. [CrossRef]

41. Mouls, L.; Fulcrand, H. Identification of new oxidation markers of grape-condensed tannins by UPLC-MS analysis after chemical depolymerization. Tetrahedron 2015, 71, 3012-3019. [CrossRef]

42. Schieber, M.; Chandel, N.S. ROS Function in Redox Signaling and Oxidative Stress. Curr. Biol. 2014, 24, 453-462. [CrossRef] [PubMed]

43. Fernandez-Panchon, M.S.; Villano, D.; Troncoso, A.M.; Garcia-Parrilla, M.C. Antioxidant Activity of Phenolic Compounds: From In Vitro Results to In Vivo Evidence. Crit. Rev. Food Sci. Nutr. 2008, 48, 649-671. [CrossRef] [PubMed]

44. Mittal, M.; Siddiqui, M.R.; Tran, K.; Reddy, S.P.; Malik, A.B. Reactive Oxygen Species in Inflammation and Tissue Injury. Antioxid. Redox Signal. 2014, 20, 1126-1167. [CrossRef] [PubMed]

45. Chen, Y.-C.; Shen, S.-C.; Lee, W.-R.; Hou, W.-C.; Yang, L.-L.; Lee, T.J.F. Inhibition of nitric oxide synthase inhibitors and lipopolysaccharide induced inducible NOS and cyclooxygenase-2 gene expressions by rutin, quercetin, and quercetin pentaacetate in RAW 264.7 macrophages. J. Cell. Biochem. 2001, 82, 537-548. [CrossRef] [PubMed]

46. Huang, W.-C.; Chang, W.-T.; Wu, S.-J.; Xu, P.-Y.; Ting, N.-C.; Liou, C.-J. Phloretin and phlorizin promote lipolysis and inhibit inflammation in mouse 3T3-L1 cells and in macrophage-adipocyte co-cultures. Mol. Nutr. Food Res. 2013, 57, 1803-1813. [CrossRef] [PubMed]

47. Tseng, A.; Zhao, Y. Wine grape pomace as antioxidant dietary fibre for enhancing nutritional value and improving storability of yogurt and salad dressing. Food Chem. 2013, 138, 356-365. [CrossRef] [PubMed]

48. Shah, N.P. Effects of milk-derived bioactives: An overview. Br. J. Nutr. 2000, 84, 3-10. [CrossRef]

49. Bertolino, M.; Belviso, S.; Dal Bello, B.; Ghirardello, D.; Giordano, M.; Rolle, L.; Gerbi, V.; Zeppa, G. Influence of the addition of different hazelnut skins on the physicochemical, antioxidant, polyphenol and sensory properties of yogurt. LWT Food Sci. Technol. 2015, 63, 1145-1154. [CrossRef]

50. Xiao, J.B.; Huo, J.L.; Yang, F.; Chen, X.Q. Noncovalent Interaction of Dietary Polyphenols with Bovine Hemoglobin in Vitro: Molecular Structure/Property-Affinity Relationship Aspects. J. Agric. Food Chem. 2011, 59, 8484-8490. [CrossRef]

51. Hutkins, R.W.; Nannen, N.L. pH Homeostasis in Lactic Acid Bacteria1. J. Dairy Sci. 1993, 76, $2354-2365$. [CrossRef]

52. Massa, S.; Altieri, C.; Quaranta, V.; De Pace, R. Survival of Escherichia coli O157:H7 in yogurt during preparation and storage at $4{ }^{\circ} \mathrm{C}$. Lett. Appl. Microbiol. 1997, 24, 347-350. [CrossRef] [PubMed]

53. Massa, S.; Trovatelli, L.D.; Canganella, F. Survival of Listeria monocytogenes in yogurt during storage at $4{ }^{\circ} \mathrm{C}$. Lett. Appl. Microbiol. 1991, 13, 112-114. [CrossRef]

54. Bruckner, R.; Titgemeyer, F. Carbon catabolite repression in bacteria: Choice of the carbon source and autoregulatory limitation of sugar utilization. FEMS Microbiol. Lett. 2002, 209, 141-148. [CrossRef]

55. Pérez-Jiménez, J.; Díaz-Rubio, M.E.; Saura-Calixto, F. Non-extractable polyphenols, a major dietary antioxidant: Occurrence, metabolic fate and health effects. Nutr. Res. Rev. 2013, 26, 118-129. [CrossRef] [PubMed]

56. Ferreira-Lazarte, A.; Kachrimanidou, V.; Villamiel, M.; Rastall, R.A.; Moreno, F.J. In vitro fermentation properties of pectins and enzymatic-modified pectins obtained from different renewable bioresources. Carbohydr. Polym. 2018, 199, 482-491. [CrossRef]

57. Wang, X.; Kristo, E.; LaPointe, G. The effect of apple pomace on the texture, rheology and microstructure of set type yogurt. Food Hydrocoll. 2019, 91, 83-91. [CrossRef]

(C) 2019 by the authors. Licensee MDPI, Basel, Switzerland. This article is an open access article distributed under the terms and conditions of the Creative Commons Attribution (CC BY) license (http://creativecommons.org/licenses/by/4.0/). 